\title{
Role of Object Imagery in Comprehending Real World Phenomena Attributes
}

\author{
Elena Fedyaeva, and Marina Ivleva* \\ Novosibirsk State Technical University, Humanities Department 20 Pr. K. Marksa 630072 Novosibirsk, Russia
}

\begin{abstract}
The paper analyzes the functioning of nouns as paragons of certain attributes characterizing various properties of the real world objects. Humans perceive the objects they see in space as possessing definite inherent attributes (shape or dimension). Perception results in the system of parametric adjectives. However, adjectives denote rather abstract meanings thus possessing a more sophisticated structure of categorial meaning in comparison with nouns. The dimensional nomination by adjectives is "vague", while nouns can actualize several attributes and create a holistic image. The factual material analysis reveals that: 1) the use of nouns as an "evaluation tool" of the objects' physical properties is due to the specific human feature to perceive the world primarily in essential, substantial or "objectified" images; 2) object images specify and simplify processing of the incoming data by cognitive structures; 3) object imagery is one of the tools to conceptualize spatial properties of the objects; 4) linguistic representation of object imagery is culture specific and depends on a grammatical structure of a given language conditioned by its historical development; 5) the English language is characterized by frequent direct nominal representation of an idea in contrast with the same idea being expressed by a simile in Russian.
\end{abstract}

\section{Introduction}

One of the distinguishing characteristics of a cognitive approach to the study of language units is the possibility to consider the known phenomena in a new perspective. For example, within the cognitive approach the apparent opposition of "subject" and "attribute" reveals some new potential for analysis, being the premise for the formation of a basic categorial meaning of cardinal parts of speech (noun and adjective).

The aim of this article is to analyze the ability of nouns to act as paragons of spatial characteristics reflecting quantitative properties of physical objects in the English language. We also attempt at exposing the specificity of knowledge structuring in noun semantics by the analysis of characteristics revealing themselves in the process of objects spatial characteristics representation.

\section{The background of the research}

Historically the noun goes back to the basic diffuse category of Name (noun) which combined the meanings of thingness, characterization and quantitiveness, with these meanings subsequently serving the basis of differentiation and formation of an object, its attributes and number [1, p. 14]. The thing or substance nouns function is naming and categorizing objects and phenomena of reality. The strategies of categorization and exemplifying by a certain category which are widely spread among nouns do not seem relevant for adjectives
$[2$, p.70]. Adjectives in the language, being a nominative attributive part of speech, reflect qualities and properties, giving substantive entities different values, properties and qualities. Therefore, the role of nouns is to categorize the objects and phenomena of reality, and that of adjectives is to provide description.

The very idea of thingness correlates primarily with the properties of the real world objects, such as shape, size, color. This fact explains the presence of the adjectives with corresponding semantics in the language ascribing these characteristics to substantive entities.

The cognitive process is known to include such operations as generalization, analysis, synthesis, comparison, contrast, imagination. Generalization is the process of abstraction from differing attributes of objects while identifying their common properties. Imagination involves the addition or complementation by the attributes which are absent at the moment, but present in the mind structures. Comparison and contrast as integral parts of the generalization process imply operations with objects attributes. Comparison involves determination of similar attributes while abstracting from distinctive ones. Since these processes are based on operations with attributes, the concept of thingness can also be considered as a way of some attributive structures manifestation. The thingness, imagery of perception and knowledge as well as cognitive processes per se occupy an important place in the speech organization of an individual, and in the psychic organization on the whole [3, p. 24-25].

\footnotetext{
Corresponding author: m.ivleva@ corp.nstu.ru
} 
Noun functioning in the role of basic spatial properties representants is conditioned by the specific feature of human mind to perceive the reality in substantial, essential, "objectified" images. Initially the concepts about quality were of sensory-substantial character. The quality was seen via a sensory perception of a real world object which was marked by a certain word in a language. This way, e.g. toughness was expressed by comparison with a stone and the concepts of «tough» and «stone» were not differentiated. First humans thought of an object and its attribute as of inseparable unity. The name of the object signified the substance as well as its attributes [4, p. 21].

Object image, being a form of reality reflection in the mind, is the unit of a psychic perceptual stage or a unit of reality perception. This unit is a complex of the object's sensory properties perception which fixes in the human mind such inherent features of objects as size, form or color.

Analyzing images in the whole, Gary D. Palmer argues that "images are mental representations that begin as conceptual analogs of immediate, perceptual experience, they are, therefore, indirect conceptual analogs of the environment, broadly constructed to include society, natural phenomena, our own bodies and their organic (and mental) process, and the rest of what is often called "reality" or "the world out there" $[5, \mathrm{p}$. 46-47].

\section{The factual material analysis}

It is the ability of nouns to actualize several attributes thus constructing a holistic image that is likely to explain their use in attributive function which is secondary for this class of words. As in the examples:

1) 'Vianne?'He turned and shot me that Christmastree smile [6, p. 290].

2) Susie, a savory, unfailingly sweet friend with short blond hair and a toothpaste smile, paid me amorous visits more and more often [7, p. 4].

Here, the nomination of the nouns Christmas-tree and toothpaste to the role of paragons for comparison is conditioned by the actualization of qualitative properties related to the festive occasions (1) and whiteness (2), which allows for the interpretation of Christmas-tree smile as "a happy smile" and toothpaste smile as "a white smile."

The growing use of nouns in the role of the attribute paragons is probably due to the presence of two components in the lexical meaning of the noun: substantive and attributive. In the process of the noun semantic analysis the substantial meaning per se is seen as "substantial-attributive", i.e. some semes on a deeper level are not substantive: the number of "attributes" increases and the basic "thingness" decreases in the meaning of the noun [8, p. 68-69].
The ability of nouns to act as the intensifier of attributes expressed by adjectives is of further research interest. As in the following examples:

3) He pulls back the mint-green bedspread and the forest-green blanket, and he pushes the small, square mint-and-forest green decorative pillows, the ones Meyer just bought, onto the floor, rolling his eyes [9, p.34].

4) His silent temperament had kept him apart from the joking of the ministerial drivers in the courtyard; his ice-cold nerves and ability to drive fast and safely kept him De Gaulle's personal driver [10, p.13].

According to I. A. Vezner, in the adjective type phrases (N-Adj) the intensification of the attribute expressed by the adjective is achieved by using the noun which serves as the paragon of this attribute. Since nouns possess a higher degree of expressiveness, they are able to convey additional information when used in the function of attribute intensifiers thus revealing the word image in a new unexpected light or emphasizing the known characteristics. In addition, the semantics of these nouns may reflect the universal, inherent knowledge in all mankind, as well as ideoethnic and individual knowledge [11, p. 7-12].

These adjective type phrases date back to Old English poetry with its characteristic style. One of the key features of Anglo-Saxon alliterative verse is the rich vocabulary with vast combinatorial possibilities. An object could receive different attributes, each of which actualized new images, as i.e. is the case with a 9-line Coedmon Hymn in which God is named by 8 lexemes conditioned by the necessity to use the exact phoneme at a certain part of a line [12, p. 137]. The same requirements of alliterative verse could account for the opportunities of the N-Adj type of object description emergence:

$\begin{array}{ll}\begin{array}{l}\text { Pæt se mon ne wat } \\ \text { pe him on foldan }\end{array} & \begin{array}{l}\text { About this the man does not } \\ \text { know }\end{array} \\ \text { fægrost limped, } & \text { He, for whom on land } \\ \text { hu ic earm-cearig } & \text { It befalls most favorably, } \\ \text { iscealdne sæ } & \text { how I, pauper-miserable, } \\ \text { winter wunade } & \text { on the ice-cold sea } \\ \text { wræccan lastum, } & \text { dwelt for a winter } \\ {[13,12 \mathrm{~b}-15 \mathrm{~b}]} & \text { in the paths of exile, }\end{array}$

This type of adjectival constructions is widely spread in the English language indicating, for example, the presence of certain qualities in a characterized object/person:

5) 'Inspire that,' he repeated, standing on tiptoe to get his nose as close as possible to the mushroomshaped nozzle ... [14, p. 35].

6) Worse, one of Lorcanss brothers, Tony, had brought his family with him, including his wife, Sarah, and their eighteen-month-old baby, an apple-cheeked little girl named Lulu [15, p. 392]. 
One of the universal ways of the reality cognition reflection is explication of spatial qualitative and quantitative characteristics of objects. Owing to the fact that all objects of reality have some location and fit into their spatial environment, the indication of the position in space is a natural desire of humans. Thus, E.S. Kubrjakova notes that the differences in the methods of space comprehension are generally explained in the following manner: "one of these methods is abstracted from the person of the Observer, the other, on the contrary, is "animated" by his presence" [16, p. 90].

Since a person perceives the objects situated in space simultaneously with their inherent properties such as width, length, height and thickness, the notions of parametric relations lead to the formation of the parametric adjectives system. Their motivating semantic basis is considered to be the mental operation of identification of quantitatively measurable properties in different objects of reality. However, the analysis of the factual material showed that the nouns in the English language are capable of sufficiently bright and nontrivial transmission of quantitative characteristics (e.g. dimension) owing to the image created by the nouns.

Thus, the knowledge of the quantitative properties of natural and artificial objects acquired in the course of cognition by means of sensory perception gained large linguistic representation in nouns acting in the role of unconventional paragons of dimension reflecting a subjective parametric assessment based on a imagery comparison with a typical specimen of a class of objects. This idea can be exemplified by:

7) Keys didn't seem gratified when I handed him the encyclopedia-thick stack of curling sheets; he looked disappointed, and sent me off with a warning that next time it would be beating without the option [17, p. 56].

8) I watched as he approached the immigration official, who carefully studied Felipe's bible-thick Australian passport, scrutinizing every page, every mark, every hologram $[18, \mathrm{p} .10]$.

In the given examples, a rather indefinite meaning of the dimensional adjective thick as the carrier of the dimensional attribute is specified by the noun functioning as the paragon. Reliance on the prior knowledge, on the precedent image or paragon associated with the notions of the parametric characteristics helps to comprehend the dimension of an object (or group of objects) not in the "blurred" terms of an adjective, but in terms of specific artifacts: the image of encyclopedia or some impressively sized manual facilitates a precise representation of the object. The mental operation of categorization according to the model or paragon contributes to a more accurate as well as simple and comprehensible way of knowledge representation. The following context can be cited as an example of a detailed and explicit comparison with the same model or paragon:

9) Everyone had a file thick as the Bible in French police $H Q[10$, p. 35].
The noun milk in the following example (10) functions as a non-conventional paragon of thickness reflecting different aspects of individual perception of the artifacts:

10) Esther sips her tea from her Spode cup. The cups, which are milk-thin and gilded and slide the tea into your throat as from a porcelain spoon, are a great comfort to her [9, p. 78].

It is a well known fact that at the end of the XVIII century Josiah Spoud made a breakthrough in the porcelain industry introducing the perfect formula of bone china, the highest quality of which has become iconic, featuring a special shiny whiteness and graceful transparency. Since the image, whose mental form reflects the cognizable object or phenomenon, contains some set of attributes, it is the prevailing attributes of whiteness and transparency that determine the comparison of porcelain with milk, endowing the noun milk with the role of a imagery basis for comparison.

The noun insect in the following example (11) functions in the similar manner:

11) The frontier itself was one of those noble, striking barriers between one country and another; a high, long mountain up whose farther side we had toiled, insectsmall and hardly moving in the vastness of landscape, all the morning $[19$, p. 68].

Mental mechanisms of images transformation connected with the idea of a small in size class of animals (namely, insects) serve as at the basis of a new meaning formation - "small, as an insect", endowing the noun insect with the role of a dimensional paragon, thus becoming a linguistic sign that nominates one subject area to indicate another. It is essential that in such combinations the adjective acts as a satellite, complementing the idea of "smallness".

There is an additional adjectival example to compare the nouns and adjectives functioning as parametric markers:

12) In the bottom right-hand corner was a decentsized color photo of Mr. and Mrs. Carl Trudeau posing with their new acquisition [20, p. 69].

The data received by the subject in the process of the visual perception of the photo contributed to forming the judgment of its size as «decent», which does not allow accurate comprehension of the real photo parameters. It is accounted for by the absence of a correlation standard or some reference point relating to which there is a deviation in the direction of increase or decrease, because this paragon is largely subjective.

Unlike the nomination by means of the adjective in example (12), the reference to the size with the help of a noun seems quite definite and accurate in the following example:

13) But I suppose that's what Cordelia and I looked like then, to older people, crossing the street right here with our collars turned up... swaggering in our rubber 
boots... on our way down to Union station where the trains came in, to put our quarters into the photo machine, four shots in monochrome, wallet-sized [21, p. 132].

It is worth pointing out that almost any item of everyday life can serve as a dimensional paragon:

14) Tyler's office was exactly the same as the one next door, except that the shelves had been half filled with files and coffee-table-sized books [14, p. 27].

15) The most accurate, I was surprised to see, was the little pocket-sized Sun [17, p. 89].

16) Ruth and Dara's houses on Snowdrop Park looked exactly the same on the outside: small, two-storey redbrick houses with a post-it-sized piece of garden at the front and $a$ yard at the back [15, p. 274].

Example (14) features a coffee table as the dimensional paragon. Since there is a dimensional standard for each class of objects, being the usual, habitual size of this class of objects, the use of the noun coffee-table allows interpretation of the book size rather as "atypically large for this class of artifacts". As for example (15), the idea of a possible placing newspaper inside the pocket becomes a determinant for interpreting its size as "small". The comparison of the garden size in example (16) with re-adhesive sticker note leaflets, which were first produced by the stationery products brand "Post-it», allows comprehend the size of the garden as "tiny".

Additionally, referring to paragons is traced in some other structures connected with dimensional representation in English. For instance, the comparison of the room with the hangar in (17) forms the image of very spacious premises:

17) The doors parted silently, letting Bond, Darius and Zohreh into an enormous room, the size of an aircraft hangar, whose furthest wall contained a water-fall cascading over crimson-illuminated rocks into a pool of turquoise water in which a dozen naked women were swimming [22, p. 137].

Logically, the paragons of smallness are traditionally the nouns signifying miniature objects. The prevailing attribute "very small dimension" shapes the image thus enabling its functioning as a tool for heterogeneous entities evaluation:

\section{8) My brain is the size of a grape! [21, p. 279].}

It is also important to mention that these nominative dimensional paragons are based on peculiar individual meanings. They characterize not only physical properties of the real world objects, but also "unseen" abstract notions:

19) Even if innocence had not been conclusively proved, there was now a doubt the size of a barn door [23, p. 299]

\section{Results}

Thus, the structure $\mathrm{N}$ - Adj, with a noun acting as a paragon of spatial attributes, seems to be ample and precise in contrast with parametric attributes evaluation in terms of adjectives. It also emphasizes the nominal character of the English language. The use of English nouns as dimensional paragons consolidating a range of attributes via the constructed image is likely to be conditioned by the general tendency of the English language towards a nominative thought representation. This peculiarity of English is historically associated with the traditional for this culture respect for the facts and scientific accuracy (more on the topic in [24]). In Russian, the same idea is not likely to be expressed by an $\mathrm{N}$-Adj phrase because of the difference in the structural peculiarities of the two languages. Objet image characterization is found in numerous parametric similes, as in the example:

20) Увидев тяжело бегущчих соавторов, Вова из Коврова всплеснул руками и показал пальцем на свои золотые часы величиной хоккейную шайбу [25, p. 244].

(Having seen the heavily running co-authors, Vova from Kovrovo clasped his hands in dismay and with a finger pointed at his golden watch the size of a hockey puck - our translation)

\section{Conclusion}

Since spatial representations are actively involved in the formation of linguistic world-view, the perception of space has firmly set in language in numerous methods of parametric properties nomination.

Conceptualization of objects parametric properties includes quantitative evaluation by the subject of perception. This evaluation results in description of spatial and physical properties which can be expressed not only in conventional measuring units, but also employ individual, "custom-made" terms. Frequently, these terms are nominal dimensional paragons bearing specified meaning for the evaluator. These language units contain the observer's knowledge and opinion about a real life object. The images of these real life objects stored in human mind are not the reflections of the real material world, but the interpretation of the world by the subject of cognition. Imagery in this case can be treated as "a specific method of reality conceptualization, i.e. cognition based on visually perceived attributes" [26, p. 72].

The ability of nouns to name the objects attributes is explained by the diffuse boundaries between parts of speech as well as by the presence of common semantic zones. It is further enhanced by the correlation between the conceptual domains of quality, quantity and space; by the continuity of conceptual space and conceptual thought on the whole.

Unlike nouns, adjectives represent generalized attributes, often without reference to specified objects, and thus are characterized by a more sophisticated and 
abstract structure of categorial meaning. A noun invoking a certain object is characterized by a complex set of attributes. Consequently, a noun specifies and simplifies processing of the incoming data by cognitive structures.

\section{References}

1. L. A. Kozlova, Modern Linguistic Education: the World of the Language under Study (Barnaul, 2000)

2. I. S. Lachina, The Problems of Semantics: Psycholinguistic Research (Tver: TGU, 1991) p

3. L. V. Barsuk, A.A. Zalevskaya, Psychological Problems of Words Function-ing in Human Lexicon (Tver: TGU, 1999)

4. I. V. Il'in, Ontological and gnosiological .functions of the quality and quantity categories (Moskva: Vysshaja shkola, 1972

5. G. B. Palmer, Toward a theory of cultural linguistics (University of Texas Press, 1996)

6. J. Harris, The Lollipop Shoes (Random House, 2010)

7. D. Millman, Way of the Peaceful Warrior (New World Library, 2000)

8. V. V. Gurevich, Language: Theory, History, Typology (Moscow: Editorial URSS, 2000)

9. A. Bloom, Away (N.Y.: Random House, 2008)

10. F. Forsyth, The Day of the Jackel (Lnd.: Aroow Books, 2011)

11. I. A. Vezner, Noun Associative Potential and its Realization in the Processes of Metaphoric Emphasis Exemplified by the English Language. Abstract of theses cand. of Phil. Sci. (Barnaul, 2004)

12. P. S. Baker Introduction to Old English (John Wiley \& Sons, 2012)

13. R. Fowler, Old English Prose and Verse: An Annotated Selection, with Introductions and Notes (London: Routledge \& K. Paul, 1973)

14. S. Clarke, Merde happens (Transworld Publishers, 2008)

15. C. Kelly, Once in a Lifetime (Lnd.: Harper, 2012)

16. E. S. Kubryakova, Logical Analysis of a Language. The Languages of Space (Moscow: Yazyki russkoy kul'tury, 2000)

17. S. Faulks, Engleby (Lnd.: Vintage Books, 2008)

18. E. Gilbert, Committed (Lnd.: Penguine Books, 2011)

19. P. O'Brian, Collected Short Stories (Lnd.: Flamingo, 1995)

20. J. Grisham, The Appeal (Lnd.: Arrow books, 2008)

21. M. Atwood, Cat's Eye (Lnd.: Virago Press, 2004)

22. S. Faulks, Devil May Care (N. Y.: Vintage books, 2009)

23. F. Forsyth, The Cobr (Lnd.: Corgi Books, 2010)

24. L. A. Kozlova, Ethnocultural Potential of a Language Grammatical Structure and its
Realization in the Grammar of the Speaker (Barnaul: AltGPA, 2009)

25. Yu. Polyakov, Gypsum trumpeter: take two (Moscow: Astrel: AST, 2010)

26. V. B. Gol'dberg, Cognitive Linguistics Problems 1, 64-75 (2013) 